\title{
Comparison between Gamma Nail and Proximal Femoral Nail in Management of Unstable Intertrochanteric Fractures
}

\author{
Ali Nassem Ali Mohamed ${ }^{1, *}$ MSc; Younis Mahmoud Mohamed Akl ${ }^{2}$ MD ; Ahmed Ismail Ahmed \\ Hammouda ${ }^{2}$ MD
}

*Corresponding Author:

Ali Nassem Ali Mohamed alimansor@gmail.com

Received for publication December 29, 2020; Accepted january 31, 2021; Published online january 31, 2021

Copyright 2021 The Authors published by Al-Azhar University, Faculty of Medicine, Cairo, Egypt. All rights reserved. This an openaccess article distributed under the legal terms, where it is permissible to download and share the work provided it is properly cited. The work cannot be changed in anyway or used commercially.

doi: 10.21608/aimj.2021.55791.1389

${ }^{l}$ Orthopedic Surgery Department, Ahmed Maher Teaching Hospital, Cairo , Egypt

${ }^{2}$ Orthopedic Surgery Department, Faculty of Medicine, Al-Azhar University, Cairo, Egypt.

\begin{abstract}
Background: Proximal femoral fractures have been on the rise with the increase in life expectancy and osteoporosis in the elderly population and road traffic accidents among the younger counterparts.

Aim of work: are to evaluate and compare the outcome $f$ using either Gamma nail or Proximal femoral nail in internal fixation of unstable intertrochanteric fractures regarding preoperative parameters, intraoperative variables, postoperative complications. Patient and Methods: A prospective study on 30 cases suffering from unstable intertrochanteric fractures managed using either Gamma Nail or Proximal femoral nail to assess the functional and radiological results.

Results: There was a significant difference found between the two groups regarding intraoperative blood loss $(\mathrm{ml})$. There was no significant difference found between the two groups regarding DVT, Infection, Implant failure, and non-union. There was a significant difference found between the two groups regarding the Time of union (months).

Conclusion: Our study showed that both gamma nail and proximal femoral nail are trusted implants for the surgical management of unstable trochanteric fractures in patients with a high rate of union but with differences in the time of union, less intraoperative blood loss, and fewer postoperative complications rate.

Keywords: Gamma Nail; Proximal Femoral Nail; Unstable Intertrochanteric Fractures.

Disclosure: The authors have no financial interest to declare in relation to the content of this article. The Article Processing Charge was paid for by the authors.

Authorship: All authors have a substantial contribution to the article.
\end{abstract}

\section{INTRODUCTION}

Proximal femoral fractures have been on the rise with the increase in life expectancy and osteoporosis in the elderly population and road traffic accidents among the younger counterparts. ${ }^{1}$

Intertrochanteric fractures in young patients are generally because of a major trauma as road traffic accident or fall from height. $90 \%$ of intertrochanteric fractures in old patients result from a simple fall. The tendency to fall is exacerbated by many factors such as osteoporosis, vascular disease, and coexisting musculoskeletal pathology. ${ }^{2}$

A high mortality rate after fracture of the hip is commonly with advanced age, untreated or poorly controlled systemic disease, internal fixation before control of co-morbidities, and postoperative complications. $^{3}$

The goals of management of any hip fractures, other than reducing mortality, is to return patients safely

and efficiently to their pre-fracture level of function without prolonged disability and preventing different complications and to give the patient sufficient independence. Rigid fixation with early patient mobilization must be considered as the standard treatment. This significantly improves the ability to walk and rapid return to normal life. ${ }^{4}$

In this study, we studied the various aspects of Gamma nail and proximal femoral nail in fixation unstable intertrochanteric fractures. We assumed that PFN significantly reduces the operative time, amount of blood loss and offers significant benefits in terms of post-operative functional recovery or complications as compared to Gamma nail

\section{PATIENTS AND METHODS}

A prospective study was conducted between January 2020 to December 2020 involving 30 patients with unstable intertrochanteric fractures and managed with reduction (open or closed) and internal fixation using either Gamma Nail (GN) or proximal femoral nail (PFN)

Methodology 
Pre-operative, intraoperative and post-operative components.

Preoperative component:

It includes:

Patient selection:

Inclusion criteria:

Unstable trochanteric fractures according to Evans classification for trochanteric fractures: Fig. (1)

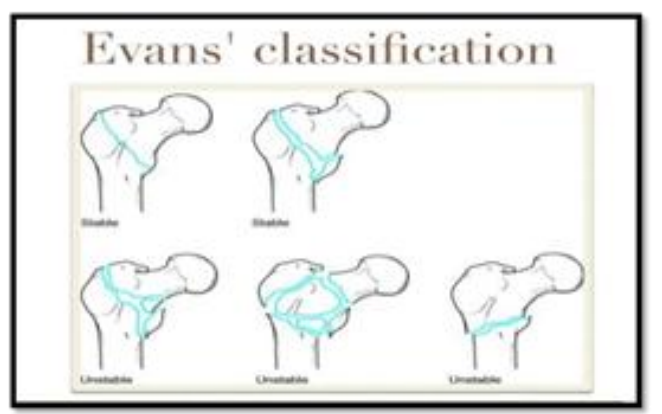

Fig. 1: Evans classification of trochanteric fracture. ${ }^{6}$ In our study all the cases were classified as unstable fracture.

Exclusion criteria:

Patients less than 18 years.

Other fractures or dislocation in the same limb.

Paralytic limb

Preoperative preparation of the patient:

Preoperative hemoglobin (HB) was at least $10 \mathrm{~g} / \mathrm{dl}$ in all patients.

40 I.U. LMWH was started routinely unless there was any risk factor for bleeding since time of fracture, and stopped 12 hours before surgery then continued postoperatively as daily dose for 4 weeks after the surgery.

Operative procedure

Anesthetic technique: Fig. (2)

Anesthetic technique was a decision of the anesthetist according to the expected duration of surgery, patient health status and intraoperative conditions according to American Society of Anesthesiology classification (ASA score): ${ }^{5}$

\begin{tabular}{|l|l|}
\hline Classification & \multicolumn{1}{|c|}{ Description } \\
\hline ASA 1 & Healthy patients \\
\hline ASA 2 & $\begin{array}{l}\text { Mild to moderate systemic disease caused by the } \\
\text { surgical condition or by other pathological processes, } \\
\text { and medically well controlled }\end{array}$ \\
\hline ASA 3 & $\begin{array}{l}\text { Severe disease process which limits activity but is not } \\
\text { incapacitating }\end{array}$ \\
\hline ASA 4 & $\begin{array}{l}\text { Severe incapacitating disease process that is a constant } \\
\text { threat to life }\end{array}$ \\
\hline ASA 5 & $\begin{array}{l}\text { Moribund patient not expected to survive 24 hours with } \\
\text { or without an operation }\end{array}$ \\
\hline ASA 6 & $\begin{array}{l}\text { Declared brain-dead patient whose organs are being } \\
\text { removed for donor purposes }\end{array}$ \\
\hline
\end{tabular}

Fig. 2: American Society of Anesthesiology classification.

\section{Antibiotics:}

Single dose of third generation cephalosporin was given intravenously for each patient intraoperatively and was continued postoperatively every 12 hours for 7 days. Operative technique: ${ }^{7}$

In Gamma nail, it can be done with or without a traction table. Usage of traction table, the lower limb must be adducted to assist nail insertion. Incision of skin is five $\mathrm{cm}$ proximal to greater trochanter tip, after dissection of the superficial fascia and muscles, after awling greater trochanter the guide $\mathrm{k}$-wire is introduced under $\mathrm{x}$-ray guide into greater trochanter. The guide K-wire is introduced into the center of femoral shaft in both $\mathrm{x}$-ray views. The proximal part of femur is manually drilled using rigid reamer. The nail is manually inserted into femoral shaft. Using the aiming arm, which is connected to the insertion device, the guide k-wire for lag screw is inserted firstly into neck of femur in a way which the screw will be placed into central part on a lateral $\mathrm{x}$-ray view and inferior half of the neck on the anteroposterior $\mathrm{x}$-ray view.

In PFN, the same occurs except there is an antirotational screw, the guide $\mathrm{K}$-wire for anti-rotational screw was inserted. The anti-rotational screw is inserted firstly with the tip just about $25 \mathrm{~mm}$ medial to the fracture line; then, lag screw is inserted. Lastly, distal screws are either dynamically or statically.

Post-operative evaluation

Patients were followed up at regular visits at $2 \mathrm{~W}$, $6 \mathrm{~W}, 3 \mathrm{M}, 6 \mathrm{M}$. At each follow up visit the patient had clinical and radiological examination.

Clinical examination and clinical scores

Leg length discrepancy.

The presence of thigh pain or hip pain.

Harris Hip Score (Fig. 2). ${ }^{8}$

Radiological evaluation

Reduction quality:

It was evaluated by measurement of neck-shaft angle of operated side on anteroposterior view which is normally 125 degree. Less than five degrees variation from the normal range is considered a good reduction, between 5 and ten degrees of variation is considered accepted and less than ten degrees variation is considered poor reduction. ${ }^{9}$

Fixation quality:

It was measured using tip apex distance which was defined by Baumgaertner et al. ${ }^{10}$ and Cleveland et al. index ${ }^{(11)}$. A tip-apex distance $<25 \mathrm{~mm}$ prevents cutting out of screw from head of femur and was considered sufficient for both type of nails. The Cleveland index was used to assess the placement of the lag screw. A center-inferior or center-center position of the lag screw is considered optimal.

Union of the fracture:

It was assessed by follow up x-ray series postoperatively at six weeks, 12 weeks, six months, one year. 


\begin{tabular}{|c|c|}
\hline \multicolumn{2}{|l|}{ Pain } \\
\hline None & 44 \\
\hline Slight, occasional & 40 \\
\hline Mild, normal activity & 30 \\
\hline Moderate, activity concessions & 20 \\
\hline Marked, severe concessions & 10 \\
\hline Totally disabled & 0 \\
\hline \multicolumn{2}{|l|}{ Range of motion (ROM) } \\
\hline Full & 5 \\
\hline Partial* & 4 \\
\hline Limited* & 2 \\
\hline \multicolumn{2}{|l|}{ Gait/limp } \\
\hline None & 11 \\
\hline Slight & 8 \\
\hline Moderate & 5 \\
\hline Unable to walk & 0 \\
\hline \multicolumn{2}{|l|}{ Gait/support } \\
\hline None & 11 \\
\hline Cane for long walks & 7 \\
\hline Cane, full time & 5 \\
\hline Crutch & 4 \\
\hline Two canes & 2 \\
\hline Unable to walk & 0 \\
\hline \multicolumn{2}{|l|}{ Gait/distance } \\
\hline Unlimited & 11 \\
\hline 6 blocks & 8 \\
\hline 2 or 3 blocks & 5 \\
\hline Indoors only & 2 \\
\hline Bed and chair & 0 \\
\hline \multicolumn{2}{|l|}{ Function/stairs } \\
\hline Normal & 4 \\
\hline Normal with banister & 2 \\
\hline Any method & 1 \\
\hline Unable & 0 \\
\hline \multicolumn{2}{|l|}{ Socks and shoes } \\
\hline Easy & 4 \\
\hline With difficulty & 2 \\
\hline Unable & 0 \\
\hline \multicolumn{2}{|l|}{ Sitting } \\
\hline Any chair 1 hour & 5 \\
\hline High chair $1 / 2$ hour & 3 \\
\hline Unable to sit $1 / 2$ hour & 0 \\
\hline \multicolumn{2}{|l|}{ Public transport } \\
\hline Able & 1 \\
\hline Not able to use & 0 \\
\hline \multicolumn{2}{|l|}{ Deformity $^{+}$} \\
\hline Absence of all 4 & 4 \\
\hline Presence of 1 & 0 \\
\hline
\end{tabular}

Fig. 3: Harris Hip Score. ${ }^{8}$

\section{RESULTS}

The study was conducted on 30 patients, 15 cases treated with Gamma Nail and 15 cases treated with proximal femoral nail.

Analysis of our results shows that operative time is more in PFN with average $63.4 \mathrm{~min}$. than GN with average 57.33 min., blood loss in PFN more than GN. Table (1)

HHS score of proximal femoral nail patients with average $85.77 \%$ is better than these of GN with average $83.14 \%$. Table (2).

There is single case in each group developed DVT but no one developed pulmonary embolism, 2 patients in PFN and one in GN developed superficial wound infection. Time of union in GN took more time than PFN. Implant failure in PFN is more than GN Table (3).

Implant failure: there is a single case in PFN and 2 in GN developed cut throw after 3 months of follow up (fig. 4), there is only case has broken PFN after 6 months of follow up (fig. 5), there 2 cases in PFN and single case in GN have back out (fig. 6). Table (3)
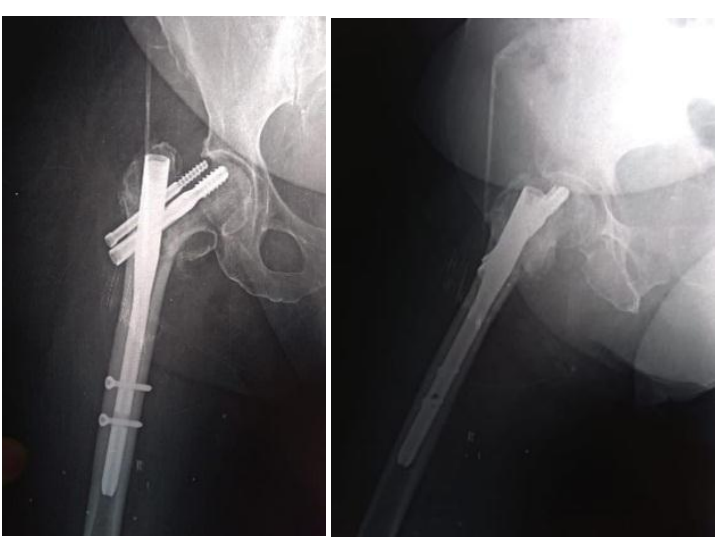

Fig. 4: case of cut throw after of 3 months of fixation using PFN.

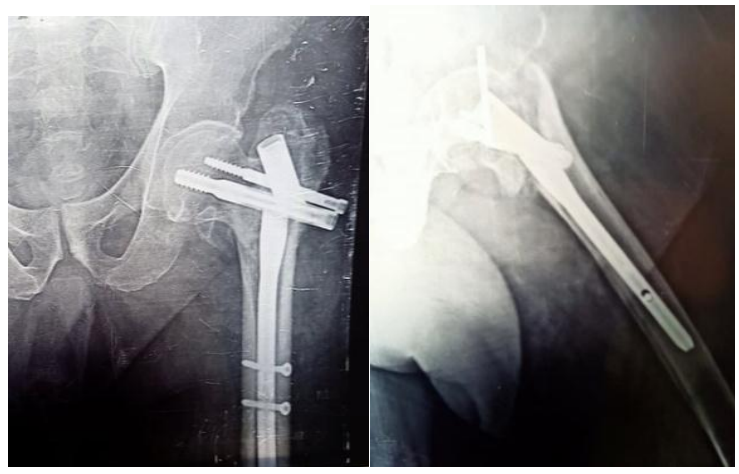

Fig. 5: case of broken PFN after of 6 months of fixation using PFN.
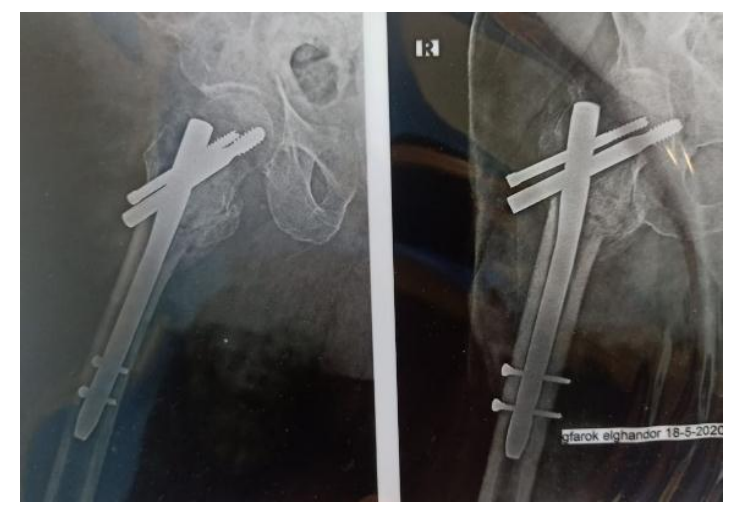

Fig. 6: case of back out after of 4 months of fixation using PFN.

\begin{tabular}{|c|c|c|c|}
\hline \multicolumn{2}{|c|}{} & PFN & GN \\
\cline { 3 - 4 } \multicolumn{2}{|c|}{} & No. $=15$ & No. $=15$ \\
\hline Operation & Mean \pm & $63.40 \pm$ & $57.33 \pm$ \\
time (min) & SD & 15.60 & 10.50 \\
\cline { 2 - 4 } & Range & $45-90$ & $40-70$ \\
\hline Blood loss & Mean \pm & $165.00 \pm$ & $124.67 \pm$ \\
$(\mathrm{ml})$ & SD & 51.58 & 29.97 \\
\cline { 2 - 4 } & Range & $100-250$ & $100-200$ \\
\hline
\end{tabular}

Table 1: Comparison between regarding Operation time (min) and Blood loss (ml). 


\begin{tabular}{|c|c|c|c|}
\hline & PFN & GN \\
\hline & & No. $=15$ & No. $=15$ \\
\hline \multirow[t]{2}{*}{$\begin{array}{l}\text { HHS } \\
\text { score }\end{array}$} & $\begin{array}{c}\text { Mean } \pm \\
\text { SD }\end{array}$ & $85.77 \pm 6.70$ & $\begin{array}{c}83.14 \pm \\
6.38\end{array}$ \\
\hline & Range & $74-96$ & $75-96$ \\
\hline
\end{tabular}

Table 2: Comparison regarding HHS score.

\begin{tabular}{|c|c|c|c|}
\hline \multicolumn{2}{|c|}{} & PFN & GN \\
\cline { 3 - 4 } & No.= 15 & No. $=15$ \\
\hline \multirow{4}{*}{ DVT } & No & 14 & 14 \\
& Yes & $(93.3 \%)$ & $(93.3 \%)$ \\
& & $1(6.7 \%)$ & $1(6.7 \%)$ \\
\hline Infection & No & 13 & 14 \\
& Yes & $(86.7 \%)$ & $(93.3 \%)$ \\
& & 2 & $1(6.7 \%)$ \\
\hline Implant failure & Back out & 2 & $1(6.7 \%)$ \\
& & $(13.3 \%)$ & \\
\cline { 2 - 4 } & Broken & $1(6.7 \%)$ & $0(0.0 \%)$ \\
\cline { 2 - 4 } & nail & & \\
\cline { 2 - 4 } & Cut & $1(6.7 \%)$ & 2 \\
& through & & $(13.3 \%)$ \\
\cline { 2 - 4 } & No & 11 & 12 \\
& & $(73.3 \%)$ & $(80.0 \%)$ \\
\hline \multirow{2}{*}{$\begin{array}{c}\text { Time of union } \\
\text { (months) }\end{array}$} & Mean \pm & $2.64 \pm$ & $3.33 \pm$ \\
& SD & 0.50 & 0.82 \\
\cline { 2 - 4 } & Range & $2-3$ & $2-5$ \\
\hline
\end{tabular}

Table 3: Comparison regarding DVT, Infection, Implant failure, Time of union (months).

\section{DISCUSSION}

Intertrochanteric fractures always have a history of Intertrochanteric fractures in younger individuals are usually due to a high-energy trauma or fall from a height. $90 \%$ of intertrochanteric fractures in old patients result from simple fall. The susceptibility to fall is aggravated by different factors as osteoporosis, vascular disease, and coexisting musculoskeletal pathology. Women are three times more liable to this type of fracture. ${ }^{13}$

The aim of management of patients with intertrochanteric fractures was to minimize the death rate, mortality rate, and early limb mobility. 14,15

The goal of this work was to study the various aspects of Gamma nail and PFN in fixation unstable intertrochanteric femur fractures. Patients were divided randomly into 2 groups and each group contained 15 patients to undergo and internal fixation with either standard gamma nail or PFN. They were compared regarding preoperative variables, intraoperative variables and postoperative parameters.

Our study revealed that there is no statistically significant difference between two groups regarding sex, age, fracture side and mode of trauma.

In Ahmed et al. ${ }^{16}$ study, almost two-thirds of the patients were females that supports our results. This majorityof females is similar to that noticed across several studies conducted among patients with unstable intertrochanteric fractures.

On the contrary, the mean age of patients of our study is lower than that found in other studies such as Mereddy et al. ${ }^{17}$ who in their study of PFN recorded a mean age of seventy-eight years. Loubignac et al. ${ }^{18}$ also showed a mean age of 80.3 years among their cases with fixation of trochanteric fractures. In this study, the mean age of the patients was 68.87 years.

The mean of blood loss was higher in GN group in Schipper et al. ${ }^{19}$ which counter act the results of our study which revealed that blood loss was high in PFN group.

Also, Time of operation and intraoperative blood loss are less in PFN patients in comparison with gamma nail patients in Morihara et al. ${ }^{20}$, because reaming is not necessary.

In Domingo et al study of 295 unstable intertrochanteric fractured patients with managed with the PFN. ${ }^{21}$ they found that surgical technique is simple, the number of recorded complications was accepted, and noted total results were comparable with that of other studies.

In study of Banan et al. ${ }^{22}$ on 50 patients with unstable trochanteric Fractures, only case of implant failure was seen 7 months post-operatively on contrary of our study that we have 4 cases in PFN only.

In, Khare et al. ${ }^{23}$ study, the mean age of the patient was 57.7 years and mean time for union was 17.57 weeks that took longer time than our patients, the mean HHS score 86.50 at 1 year which supports our results.

Also, our study revealed that there is no significant difference found between two groups regarding associated fractures, Fracture pattern, ASA score, Interval before surgery (days), Time of operation (min), Hospital stay (days) and Post op. blood while there is significant difference found between two groups regarding intraoperative blood loss (ml).

Regarding the post-operative complications, there was no significant difference found between two groups regarding DVT, Infection, Implant failure and non-union, but on the other hand there was statistically significant difference found between 2 groups regarding union time (months).

\section{CONCLUSION}

Our study showed that both gamma nail and proximal femoral nail are trusted devices for internal fixation of unstable trochanteric fractures in patients with high union rate but with difference in the time of union, less intraoperative loss of blood, and fewer post-operative complications rate. 


\section{REFERENCES}

1. Bucholz R, Hechman J, Courtbrown C. Intertrochanteric fractures. Rockwood \& Greens Fractures in adults, 6th edition. 2006. P. 1794810.

2. Subasi M, Kesemenli C, Kapukaya A, et al. Treatment of intertro-chanteric fractures by external fixation. Acta OrthopBelg .2001; 67: 46874.

3. Zuckerman JD. Comprehensive care of orthopaedic injuries in the elderly. Baltimore: Urban and Schwarzenberg, 1990.

4. Jabshetty AB. Management of intertrochanteric fracture by DHS fixation. Ind J Sci Tech .2011; 4: 1681- 84.

5. American Society of Anesthesiologists. ASA Physical Status Classification System. Last approved by the ASA House of Delegates on October 15, 2014.

6. Liu XZ, Wen Y, Yang SH, et al. Total hip arthroplasty for treatment of elderly patients with comminuted intertrochanteric fracture accompanied by femoral head necrosis. Chinese Journal of Traumatology (English Edition). 2008; 11(6): 359-63.

7. Panchanadikar V. Proximal Femur Nail in Intertrochanteric Fractures Indications and Tips/Tricks, MOJ Orthopedics \& Rheumatology, 2016; 3(5): 178.

8. MacDonald CW, Whitman JM, Cleland JA, et al Clinical outcomes following manual physical therapy and exercise for hip osteoarthritis: a case series. Journal of Orthopaedic\& Sports Physical Therapy. 2006; 36(8): 588-99.

9. Karapinar L, Kumbaraci M, Kaya A, et al. Proximal femoral nail anti-rotation (PFNA) to treat peritrochanteric fractures in elderly patients. Eur $J$ Orthop Surg Traumatol. 2012; 22: 237-43.

10. Baumgaertner MR, Curtin SL, Lindskog DM, et al. The value of the tip-apex distance in predicting failure of fixation of peri- trochanteric fractures of the hip. J Bone Joint Surg Am. 1995; 77: 1058-64.

11. Cleveland M, Bosworth DM, Thompson FR, et al. Ten-year analysis of intertrochanteric fractures of the femur. J Bone Joint Surg Am. 1959; 41(A): 1399408.

12. Li YH, Yu T, Shao W, et al. Distal locked versus unlocked intramedullary nailing for stable intertrochanteric fractures, a systematic review and meta-analysis. BMC MusculoskeletDisord. 2020; 21(1): 461.

13. Ju JB, Zhang PX, Jiang BG. Risk Factors for Functional Outcomes of the Elderly with Intertrochanteric Fracture: A Retrospective Cohort Study. Orthop Surg. 2019; 11(4): 643-52.

14. Mattisson L, Bojan A, Enocson A. Epidemiology, treatment and mortality of trochanteric and subtrochanteric hip fractures: data from the Swedish fracture register. $B M C$ MusculoskeletDisord. 2018;19(1): 369.

15. Cheng YX, Sheng X. Optimal surgical methods to treat intertrochanteric fracture: a Bayesian network meta-analysis based on 36 randomized controlled trials. J Orthop Surg Res. 2020; 15(1): 402.

16. Ahmed HH, Bassiooni HA, Mohamady EM, et al. A comparison study of proximal femoral nail and dynamic hip screw devices in unstable trochanteric fractures. Benha Med J .2018; 35: 413-8.

17. Mereddy P, Kamath S, Ramakrishnan M, et al. The AO/ASIF proximal femoral nail (PFN): a new design for the treatment of unstable proximal femoral fractures. Injury .2009; 40: 428-32.

18. Loubignac F, Chabas JF. A newly designed locked intramedullary nail for trochanteric hip fractures fixation: Results of the first 100 trochanteric implantations. OrthopTraumatol Surg Res. 2009; 95: 139-44.

19. Schipper IB, Steyerberg EW, Castelein RM, et al Treatment of unstable trochanteric fractures: randomised comparison of the gamma nail and the proximal femoral nail. The Journal of bone and joint surgery. British volume. 2004; 86(1): 86-94.

20. Morihara T, Arai Y, Tokugawa S, et al. Proximal femoral nail for treatment of trochanteric femoral fractures. J Orthop Surg (Hong Kong). 2007; 15(3): 273-7.

21. Domingo LJ, Cecilia D, Herrera A, et al. Trochanteric fractures treated with a proximal femoral nail. Int Orthop. 2001; 25(5): 298-301.

22. Banan H, Al-Sabti A, Jimulia $T$, et al. The treatment of unstable, extracapsular hip fractures with the AO/ASIF proximal femoral nail (PFN)-our first 60 cases. Injury. 2002; 33(5): 401-5.

23. Khare GN, Belbase RJ, Singh S, et al. Outcome Analysis of Reverse Oblique Trochanteric Fractures Treated with Proximal Femoral Nail. Journal of Bone and Joint Diseases .2018; 33(1): 20-3. 